\title{
OBJETIVOS DE DESENVOLVIMENTO DO MILÊNIO: PERSPECTIVAS A PROMOÇÃO DA IGUALDADE DE GÊNERO E AUTONOMIA DAS MULHERES
}

\author{
Jonathan Barros Vita ${ }^{1}$ \\ Patrícia Silva Almeida ${ }^{2}$
}

\section{RESUMO}

O presente ensaio visa apresentar análise relativa à promoção da igualdade de gênero e autonomia das mulheres junto aos avanços dos Objetivos de Desenvolvimento do Milênio; na sequência descrevem-se os dados apresentados pelo Instituto de Pesquisa Econômica Aplicada - IPEA, acerca do "Retrato da desigualdade de gênero", no âmbito do Sistema de Indicadores de Percepção Social (SIPS), foco na "tolerância institucional", uma amostra representativa do conjunto da população brasileira, com objetivo da aferir a "tolerância social do gênero", por fim; discorre-se sobre o efetivo alcance da meta e a nova proposta de trabalho dos objetivos em desenvolvimento para os próximos anos.

Palavras-chaves: Autonomia da mulher; Igualdade de gênero; Objetivos de desenvolvimento do milênio; Organizações das Nações Unidas; Tolerância de gênero.

\section{MILLENNIUM DEVELOPMENT GOALS: PERSPECTIVES TO PROMOTE GENDER EQUALITY AND WOMEN'S AUTONOMY}

\begin{abstract}
The present essay aims to present an analysis referring to the gender equality and women's autonomy together with the Millennium Development Goals; then it describes the data presented by the Institute for Applied Economic Research - IPEA concerning the "Faces of gender inequality" in the scope of the Social Perception System of Indicators (SIPS) focusing on the perception of "institutional tolerance", a representative sample of the Brazilian population set with the purpose of assessing the "social tolerance of gender"; and finally, it tells about the effective target range and the new work proposal for the developing goals over the coming years.
\end{abstract}

Keywords: Women's autonomy. Gender equality. Gender tolerance. Millennium Development Goals. United Nations.

\footnotetext{
${ }^{1}$ Doutor e Mestre em Direito pela Pontifícia Universidade Católica de São Paulo - PUCSP. Mestre em Segundo Nível em Direito Tributário de Empresa pela Universitá Commercialle Luigi Bocconi - Milão (Itália). Especialista em Direito Tributário pelo Instituto Brasileiro de Estudos Tributários - IBET. Coordenador e Professor Titular do Programa de Doutorado e Mestrado em Direito da Universidade de Marília - UNIMAR. Advogado. Consultor Jurídico. Contador. E-mail: jbvita@gmail.com Lattes: http://lattes.cnpq.br/6200020135164378

${ }^{2}$ Mestranda em Direito pela Universidade de Marília - UNIMAR. Especialista em Direito Público pela Escola da Magistratura Federal do Rio Grande do Sul - ESMAFE/RS. Oficiala Registradora e Tabeliã de Notas do Município de Santa Salete, Estado de São Paulo. E-mail: jpalmeida@ via-rs.com.br Lattes: http://lattes.cnpq.br/5522757486165755
} 


\section{CONSIDERAÇÕES INICIAIS}

Os movimentos em prol da igualdade de gênero não têm sido na atualidade, projetos meramente teóricos. Várias correntes feministas demandam e propõem estudos acerca do tema, o que tem gerado transformações nos discursos e nas necessidades de superação da discriminação contra o gênero feminino e reclames por sua maior autonomia.

A vivência, nos últimos anos, tem demonstrado uma preocupação com projetos de inserção social e empoderamento feminino, passando a ser objeto de discussão frente aos órgãos nacionais e internacionais sobre o progresso efetivo em relação à igualdade entre os gêneros.

Neste contexto, a Organização das Nações Unidas - ONU -, em setembro de 2000, em Reunião Plenária de Alto Nível da Assembleia Geral da ONU, através de seus membros reunidos em Nova Iorque, estabeleceram um conjunto de metas pactuadas pelos governos dos 191 países-membros, metas estas que geraram a Declaração do Milênio das Nações Unidas.

Os países-membros acordaram os "Oito objetivos do Milênio", revistos no prazo de quinze anos (até 2015), visando solucionar alguns problemas da humanidade, entre eles, promover o máximo alcance da igualdade entre gêneros e instigar a autonomia feminina.

A escolha do tema se justifica frente à vivência e discussões fomentadas pelos dados da pesquisa realizada pelo Instituto de Pesquisa Econômica Aplicada - IPEA, abordando o "Retrato das desigualdades de Gênero e raça no Brasil", onde as preocupações com a discriminação de gênero e alarmante violência, e descaso, persistem, muito embora exista a preocupação dos órgãos governamentais e internacionais sobre o assunto.

Para tanto, didaticamente, o desenvolvimento do artigo far-se-á da seguinte forma. Primeiramente, abordar-se-á no tópico "Os Objetivos de Desenvolvimento do Milênio: um olhar do mundo sobre os problemas sociais envolvendo as mulheres", o surgimento dos movimentos feministas e seus discursos teóricos na tentativa de explicar as desigualdades de gênero, assim como irá discorrer sobre o trabalho da Organização das Nações Unidas, na Cimeira do Milênio, uma proposta que comportou metas, com o intuito de sensibilizar o mundo, a buscar solucionar alguns problemas sociais, entre eles, firmar a essência da dignidade da pessoa humana.

Em segundo momento, colocar-se-á em destaque "Apontamentos sobre as pesquisas do Instituto de Pesquisa Econômica Aplicada (IPEA) sobre desigualdade de gênero e violência contra as mulheres no Brasil", um estudo representativo da atual situação do gênero 
no país, razão pela qual acompanhamos o desenvolver das pesquisas sobre a realidade das mulheres brasileira no campo educacional, profissional e familiar; bem como avante lançar um olhar crítico sobre a violência sobre o gênero, uma realidade impactante em nosso país.

$\mathrm{E}$, por último, descreve-se a partir do tópico " $O$ alcance da meta de promoção a igualdade feminina proposta nos Objetivos de Desenvolvimento do Milênio", uma breve análise realizada a partir do relatório elaborado pela ONU, em 2015, o qual consolida lacunas existentes, embora possa ser demonstrado alguns avanços significativos nos diversos objetivos propostos, apesar de elencar as diferenças socioeconômicas existentes no mundo globalizado.

Como metodologia geral, optou-se pelo método hipotético-dedutivo, e quanto ao procedimento técnico, trata-se de um apanhado essencialmente bibliográfico, analíticodocumental, realizado com base em doutrina e nos dados de pesquisa lançados pelo Instituto de Pesquisa Econômica Aplicada.

Por fim, cabe advertir que o tema revela possíveis desdobramentos futuros e, frente às complexidades que envolvem a questão, trataremos sobre possíveis caminhos para a solução das dificuldades encontradas à promoção da igualdade entre homens e mulheres.

\section{OS OBJETIVOS DE DESENVOLVIMENTO DO MILÊNIO: UM OLHAR DO MUNDO SOBRE OS PROBLEMAS SOCIAIS ENVOLVENDO AS MULHERES}

\subsection{Da igualdade entre gêneros e a luta pela autonomia feminina}

A questão que surge em torno dos Objetivos de Desenvolvimento do Milênio, compreender o alcance de pensamento sobre os movimentos nacionais e transnacionais de proteção a igualdade entre gêneros, em especial, o ponto relacionado às demandas sociais envolvendo as mulheres e a luta por sua autonomia. ${ }^{3}$

Historicamente, a trajetória do gênero mulher é marcada por ausências, submissões e obediência aos padrões impostos pelo gênero homem. Neste contexto, o lugar ocupado pela mulher na sociedade era inexistente; deveria abster-se de quaisquer manifestações sobre sentimentos, opiniões e desejos, e sempre era renegada sua presença pública e política,

\footnotetext{
3 A luta por reconhecimento é concebida como a evolução de um processo social que leva a um aumento de comunitarização, no sentido de um descentramento das formas individuais de consciência. Há quem deseja aprofundar vide a obra Luta por reconhecimento: a gramática moral dos conflitos sociais de Axel Honneth.
} 
devendo ser desconsiderada sua força produtiva, apesar de ser existente (CORRALO; GIRELLI, 2015).

Fadigadas de sua sujeição a esse universo, as mulheres começaram a formação de movimentos feministas às conquistas de seus direitos, mormente, no que tange aos seus direitos políticos e sociais, embora lentos e gradativos.

Destaca-se ao logo da história, com intuito de reivindicar os objetivos de proteção as mulheres, surgiram vários movimentos feministas que originaram extensos discursos teóricos na tentativa de encontrar alternativas as questões que envolvem as igualdades entre os gêneros, estabelecendo programas e firmando teses, em prol da inexistência hierárquica entre os sexos, como sendo um objetivo de construção social (GIDDENS, 2007).

O feminismo e suas reivindicações sociais, sempre se apresentaram significativos na esfera do transnacional e, conforme descreve Isabel Turégano, à medida que suas demandas foram se tornando válidas, ultrapassam as fronteiras da soberania dos Estados, como afirma:

\footnotetext{
La situación de opresión, subordinación y desigualdade de las mujeres tiene características similares em todas las sociedades y em todos los momentos, a pesar de sus diferencias nacionales, étnicas o económicas. La crítica feminista no es específica de uma nación o etnia, sino que hace referencia a um tipo de dominación y subordinación que comparten diferentes naciones y diferentes grupos sociales. ${ }^{4}$ (TURÉGANO, 2012, p. 395)
}

E frente a deficiente inclusão das mulheres nos diversos planos de igualdade, (político, jurídico, educacional, econômico e social), existem esforços conscientes de ações não apenas de grupos e movimentos privados, mas, principalmente, um reconhecimento de um trabalho internacional de consolidação e alianças de organismos externos como a Organização das Nações Unidas.

Inúmeros movimentos feministas e conjunta atuação da ONU mulher têm mostrado ativos na consecução de normativas e programas internacionais garantistas de direitos os quais passamos a discorrer.

4 Tradução livre: A situação de opressão, subordinação e desigualdade das mulheres têm características semelhantes em todas as sociedades e todas as vezes, apesar das diferenças nacionais, étnicas e econômicas. A crítica feminista não é de nação específica ou um grupo étnico, mas refere-se a um tipo de dominação e subordinação que compartilham diferentes nações e diferentes grupos sociais. 


\subsection{A ONU e a Cimeira do Milênio}

Perante as Nações Unidas, a década de noventa (90), foi representativa da luta das mulheres por reconhecimento mundial, sendo que na Declaração dos Direitos Humanos das Nações Unidas em Viena (1993), foi firmado os Direitos Humanos da Mulher e da Criança como parte indisponível, integrante e indivisível dos Direitos Humanos Universais.

Além disso, outros instrumentos internacionais como a Conferência do Cairo sobre População e Desenvolvimento (1994) e a Declaração de Pequim (1995) são marcos de ações de grupos feministas em âmbito internacional.

Como aborda Isabel Turégano, a pressão que os movimentos feministas têm exercido nos últimos anos, tem influído nas normativas e decisões de várias instituições junto aos países da União Européia, que tem assumido compromissos como um dos direitos fundamentais a garantia de maior igualdade e oportunidades na luta contra as desigualdades nas mais diversas frentes, estimulando o setor privado, econômico e político a visualizar os problemas persistentes (TURÉGANO, 2012).

E, pensando na problemática questão da desigualdade feminina no plano internacional, a ONU em setembro do ano de 2000, durante a Cimeira do Milênio, através de seus membros reunidos em Nova Iorque, estabeleceu metas que geraram a Declaração do Milênio das Nações Unidas.

Embora se reconheça que os ODM's não podem ser analisados como uma norma jurídica stricto sensu, em razão de não possuir um caráter vinculante, depreende-se possuir uma força coercitiva ética, isto é, representativo de coerção de um consenso mínimo internacional, com possibilidade real de efetivação (RAMOS, 2014).

Nos termos do Prefácio da Declaração do Milênio, a proposta comporta o simbolismo do Milênio para ir ao encontro das necessidades reais das pessoas de todo o mundo e sensibilizar as nações a buscar solucionar alguns dos grandes problemas da humanidade (ONU, 2000).

Neste cenário, nosso país ocupa a $85^{\circ}$ posição em desenvolvimento humano e desigualdade de gênero segundo o Relatório de Desenvolvimento Humano do Programa das Nações Unidas para o Desenvolvimento.

E, conforme descreve Heloisa Helena Barbosa e Vitor Azevedo Almeida Júnior (2017, p. 246),: “[...] embora seja um dos países em destaque no Relatório da ONU Mulheres, 
devido ao seu papel de geração de trabalho decente para as mulheres, vinte e cinco por cento têm trabalho precário isto é, que apresenta risco ou sem proteção social".

Entre as metas adotadas, os países envolvidos pactuaram em alcançar até 2015, melhorias e perspectivas de direitos fundamentais, entre eles: a liberdade, a igualdade, a solidariedade, a tolerância, o desenvolvimento sustentável, a responsabilidade comum, bem como destaca a nível mundial, a essência da dignidade da pessoa humana, como parâmetro de igualdade e equidade entre os povos.

Focaram seus esforços de discussão sobre temas como a proteção aos grupos vulneráveis, em especial, a corrente preocupação com a “[...] necessidade dos países da África”, como dito reforço das Nações Unidas (ONU, 2000, p. 5).

Todos os objetivos propostos, clamando nossa atenção ao objetivo de número três (Promover a igualdade de Gênero e autonomia das mulheres), refletem uma verdadeira atenção da sociedade civil no geral e dos governos, a alguns dos desafios que o planeta enfrenta, e vem enfrentando, paulatinamente, que poderiam se agravar no decorrer dos anos caso não despendessem uma atenção especial (GARCIA; GARCIA, 2016).

Assim, para o alcance do objetivo proposto foi estabelecida a seguinte meta, a de eliminar a disparidade entre os sexos no ensino em todos os níveis de ensino, no mais tardar até 2015 (ONU, 2000).

Como visto para longe de se percorrer certa utopia, senão estabelecer bases práticas compatíveis com o desenvolvimento social, tão necessário para nossos congêneres e gerações futuras, a meta em questão visa um trabalho de conscientização sobre a igualdade como parte de um processo de globalização contra-hegemônica. ${ }^{5}$

A primeira vista, nos parece, o alcance das metas propostas pela ONU na diminuição da desigualdade entre homens e mulheres algo puro e simples, posto que estivessem em melhores condições de abordar alguns problemas clássicos, se não fosse a total incapacidade do Estado em proporcionar espaço e garantias de representação das mulheres frente à sociedade civil e sua sub-representação nas instituições políticas.

5 Deve-se ter um olhar atento a universalização dos Direitos Humanos. O mais se deseja é que os direitos básicos como a igualdade e a liberdade, entre tantos outros, sejam amplamente considerados em qualquer lugar do mundo, desconsiderando fronteiras. Ocorre que a noção que se tem de direitos humanos de igualdade, difere do Oriente e no Ocidente, muitas vezes até mesmo em países situados em mesma região do Planeta. Portanto, deve ser também considerada a multiculturalidade de cada país. Nestes termos, vide o pensamento de Boaventura de Souza Santos. 
Vivenciamos uma crise no modelo de bem-estar social, o modelo patriarcal de estado também está a passar pelas transformações, fruto dos problemas da crise atual das instituições estatais impotentes em resolver os problemas sociais.

E muitas das dificuldades dos Estados em realizar suas funções tradicionais (garantir o mínimo existencial), limitam cada vez mais os avanços da plena igualdade entre os gêneros.

Nesta senda, a intervenção do direito internacional nos parece, como leciona Isabel Turégano (2012, p. 396): “[...] menos como una regla o una instituición que como apoderado del vocabulário de la justicia y la bondade, la solidaridad, la responsailidad y la fe". 6

Destarte, considerando o momento de transição e das constantes discussões sobre a luta pela igualdade feminina, mister se faz analisar a situação do gênero no país, razão pela qual acompanhamos o desenvolver das pesquisas sobre a realidade da desigualdade da mulher no Brasil, através dos relatórios de pesquisa do IPEA, a seguir descritos.

\section{APONTAMENTOS SOBRE AS PESQUISAS DO INSTITUTO DE PESQUISA ECONÔMICA APLICADA (IPEA) SOBRE DESIGUALDADE DE GÊNERO E VIOLÊNCIA CONTRA AS MULHERES NO BRASIL}

Entidades como a Cfêmea e a $O N U$ mulheres com o intuito de aperfeiçoar os estudos sobre a realidade sobre a desigualdade de gênero e raça, bem como descrever a opinião da população brasileira acerca das condições femininas e violência, firmaram parceria com o Instituto de Pesquisa Econômica Aplicada - IPEA, visando mensurar a questão, através de projetos de pesquisa os quais dimensionaram a realidade brasileira, para fins de retratar a problemática questão.

Os dados gerados pelo Projeto: "Retratos da desigualdade de Gênero e Raça", produziram informações significativas ao alcançar a situação dos domicílios chefiados por mulheres, no período compreendido entre os anos de 1995 a 2015.

As informações reproduzidas no corpo deste trabalho são fidedignas ao relatório divulgado e publicado pelo supramencionado Instituto de Pesquisa, e tem como objetivo disponibilizar dados sobre diferentes temáticas da vida social brasileira, com recortes simultâneos de raça, cor e sexo, utilizando dos indicadores da Pesquisa nacional por Amostra

\footnotetext{
6 Tradução livre: "Menos como uma regra ou uma instituição, como vocábulo de apoderamento, de justiça, de bondade, de solidariedade, de responsabilidade e de fé".
} 
de Domicílios, do IBGE, além de outros recortes apropriados como a localização do domicílio (urbano ou rural).

A pesquisa partiu de uma continuidade de dados históricos quanto ao crescimento de domicílios chefiados por mulheres, sendo basicamente a pessoa referência daquele domicílio entrevistado. No ano de 1995, 23\% dos domicílios brasileiros tinham mulheres como pessoas de referência dentro de seus lares; já em 2015, vinte anos depois, este número chega aos 40\%, principalmente nos domicílios urbanos.

Importante, destacar as famílias chefiadas por mulheres não são exclusivamente aquelas nas quais não há a presença masculina: em $34 \%$ delas, há a presença masculina (cônjuge ou companheiro). Contudo, observa-se o elevado número de famílias em que as mulheres não têm cônjuges e têm filhos e, nestes casos, tais famílias se encontram em maior risco de vulnerabilidade social, já que a renda média das mulheres entrevistadas, em atenção às de origem negras, continuam bastante inferior não só em relação aos homens, mas também, se comparadas às mulheres de origem branca.

Percebe-se, a ampliação do número de famílias chefiadas por mulheres parece indicar mudanças no padrão de comportamento social, demonstrando maior aceitação de modelos menos tradicionais, uma mudança de auto percepção feminina em relação à sua posição dentro da família, independente do que pensam os homens na sociedade em que estão inseridas.

No que se refere aos padrões de acesso à educação, nos últimos anos o nível de escolaridade das mulheres aumentou consideravelmente, em especial, a busca pelos bancos das universidades brasileiras. No entanto, examinando de perto a escolaridade das pessoas adultas dos grandes centros urbanos, salta aos olhos o diferencial de cor e de raça, onde as distâncias culturais se perpetuam.

Entre os anos de 1995 e 2015, duplica-se a população adulta branca com mais de 12 anos que possuem mais tempo de estudos (de 12,5\% passa para 25\%). Se considerado o mesmo período, a população feminina negra com mais de 12 anos de estudo passa apenas de $3 \%$ para $12 \%$, um aumento considerável, porém não esconde que a população negra chega somente agora ao patamar de tempo de estudo, vinte anos atrás da população branca.

Quanto ao mercado de trabalho, as barreiras para as mulheres ingressarem no mercado de trabalho se mostram presentes, apesar dos avanços das décadas passadas. Os últimos vinte anos parecem indicar que as brasileiras atingiram um "teto" de participação difícil de ser ultrapassado (entre 54-55\%), não tendo chegado a ultrapassar 60\%. Isto significa 
que quase metade das brasileiras em idade ativa está fora do mercado de trabalho e aquelas que vão para o mercado de trabalho muitas vezes encontram a barreira de encontrar uma posição.

O que representa basicamente é que a principal ocupação feminina continua sendo o emprego doméstico, ao lado do serviço público, apesar do emprego com carteira assinada ter crescido muito nos últimos vinte anos.

O emprego doméstico é a ocupação de $18 \%$ das mulheres negras e de apenas $10 \%$ das mulheres brancas. Outra tendência é o aumento do trabalho doméstico com carteira assinada, ainda que os índices continuem muito baixos, sendo quase poucos os casos divulgados na região nordeste (a informalidade e ausência de direitos ainda se faz muito presente).

A conclusão apontou como resultado pequenos avanços de inclusão social; ainda que existam esforços e algumas melhorias da esfera pública e privada em igualar os gêneros, percebe-se a permanente desigualdade entre os gêneros e outro fator indicativo de diferença entre as raças (negra e branca).

Ao tratar do tema "Sistema de Indicadores de Percepção Social: a violência contra as mulheres", segundo a pesquisa encomendada pela ONU mulheres junto ao IPEA, os dados são alarmantes. Há uma tendência dos entrevistados, em concordar em punir severamente a violência doméstica transcende as fronteiras sociais, com pouca variação segundo região, sexo, raça, idade, religião, renda ou educação.

Todavia, infelizmente, a pesquisa apresenta resultados contraditórios, como por exemplo, podemos citar a baixa tolerância da sociedade brasileira à violência contra as mulheres. Segundo consta os dados de pesquisa:

\footnotetext{
Quase três quintos dos entrevistados, 58\%, concordaram, total ou parcialmente, que "se as mulheres soubessem se comportar haveria menos estupros". E 63\% concordaram, total ou parcialmente, que "casos de violência dentro de casa devem ser discutidos somente entre os membros da família". Também, $89 \%$ dos entrevistados tenderam a concordar que "a roupa suja deve ser lavada em casa"; e $82 \%$ que "em briga de marido e mulher não se mete a colher". Há algo aparentemente paradoxal no fato de parte expressiva dos entrevistados tenderem a concordar tanto com essas últimas sentenças quanto com a que preconiza a prisão para o marido violento - que poderia ser vista como a intromissão da colher do Estado na briga do casal, com a inexorável consequência de tornar pública a lavagem da roupa suja. (IPEA, 2015, p. 4).
}

O que isso representa? Teoricamente, apesar das constantes mudanças sociais nos últimos anos, a afirmação das mulheres junto aos espaços públicos cresceu, contudo, ainda 
vivemos sob a égide de um modelo de ordenamento patriarcal e heteronormativo da sociedade, ou seja, apesar de muitas famílias chefiadas por mulheres, nossa organização social é baseada no poder masculino, na qual a norma é a heterossexualidade.

Persiste, embora silenciosa em algumas classes sociais, a desvalorização do feminino, na aceitação da violência doméstica (física ou psicológica), seja de modo efetivo ou de maneira subliminar.

Tal constatação faz identificar, que: “[...] dentro de nosso corpo social, o homem domina o corpo feminino, onde a violência parece exercer um papel fundamental” (IPEA, 2015, p. 6).

Neste contexto, nos termos observados, conclui-se que fenômeno de violência de gênero é entendido como relevante e é persistente mecanismo de submissão feminina a perpetuação de uma ordem baseada no primado do masculino sobre o feminino; naturalmente valorizado como algo natural e que pertence às relações do convívio em sociedade.

Não muitas vezes o homem tem sua responsabilidade atenuada, seja porque não estava no exercício pleno de sua consciência ou foi pressionado socialmente; já a mulher é vista como responsável pela violência, pois provocou seu instinto.

E, para efeito dessas constatações, essas mesmas concepções nos aparecem mais diversos espaços sociais, e, na maioria das vezes, são bastante explicitados.

Então, frente ao exposto, discorremos quais foram os alcances e as perspectivas em relação aos problemas envolvendo a questão das desigualdades de gênero em virtude das metas propostas pela ONU com os Objetivos ao Desenvolvimento do Milênio.

\section{O ALCANCE DA META DE PROMOÇÃO A IGUALDADE FEMININA E NOVA PROPOSTA NOS OBJETIVOS DE DESENVOLVIMENTO DO MILÊNIO}

A partir dos dados levantados pelo IPEA sobre a questão da desigualdade entre gêneros e em face à constatação das Nações Unidas aos problemas mundiais (fome, miséria, mortalidade infantil, danos ao meio ambiente, etc.), os "Oito Jeitos de Mudar o Mundo" foram implantados em meados de 2000, revistos no ano de 2015, em Reunião junto às Nações Unidas, onde se discutiu o alcance dos objetivos propostos e quais as novas metas a serem alcançadas para os próximos quinze anos.

Ao considerar o momento de transição oportuno para debate e verificação dos avanços obtidos, alguns progressos foram alcançados, entre eles, segundo dados da ONU: a) diminuição da pobreza global; b) maior número de crianças está frequentando as escolas 
primárias; c) as mortes infantis caíram consideravelmente; d) maior acesso à água potável e, por fim; e) investimentos para o combate a epidemias como a Malária, AIDS/HIV e a Tuberculose salvaram milhões de pessoas (ONU; PNUD, 2015).

As informações do último relatório (2015) divulgado pela ONU sobre os Objetivos de Desenvolvimento do Milênio apontam, no que se refere à promoção de igualdade de gênero e autonomia das mulheres, a meta não foi totalmente satisfatória; contudo apresentou alguns avanços, principalmente na área de educação.

Constata-se, que existe hoje um número maior de meninas nos bancos escolares se comparado aos últimos quinze anos (segundo dados mundiais), sendo que as regiões menos desenvolvidas do planeta, ou em desenvolvimento, atingiram em considerável proporção, a meta em todos os níveis de ensino.

Segundo descreve os sociólogos Guilherme Paiva de Carvalho e Marcília Gomes Mendes (2015), a promoção dos direitos das mulheres e as políticas de gênero na educação no Brasil, atendeu as reivindicações dos movimentos feministas e da ONU, sendo possível visualizar dois períodos significativos de aplicabilidade das metas.

O primeiro momento (1996-2003), durante o governo do Presidente Fernando Henrique Cardoso, a agenda de gênero no Brasil aparece ligada a agenda internacional demonstrando um engajamento com os Objetivos propostos; o segundo momento (20032010), durante o governo do Presidente Luiz Inácio Lula da Silva é marcado ela institucionalização das políticas de gênero, com a criação com a criação da Secretaria Especial de Políticas para as Mulheres (SPM) e a implantação de políticas educacionais de gênero através da Secretaria de Educação Continuada, Alfabetização e Diversidade do Ministério da educação (SECAD-MEC).

Como visto, a educação apareceu em nosso país como uma das principais bandeiras dos governantes à redução da desigualdade de gênero e estímulo à autonomia da mulher, na medida em que se presume que a instituição escolar possibilita melhores oportunidades de acesso ao mercado de trabalho e se apresentar o fato como incontestável forma de propiciar a emancipação feminina.

Além disso, segundo o relatório da ONU acerca das metas alcançadas, as mulheres, no agora, ocupam $41 \%$ dos postos de trabalho remunerados além do setor agrícola, um aumento significativo se comparado aos índices levantados pela ONU, na década de 90 (ONU; PNUD, 2015). 
No entanto, cumpre destacar que a diferença de gênero está muito presente nas carreiras seguidas pelas mulheres e homens, um aspecto que evidencia o desempenho do meio escolar na formação de valores à formação das identidades de gênero, pois, constata-se que as mulheres são direcionadas a atividades profissionais de cuidado (enfermagem, por exemplo) e cultura, a citar, as licenciaturas no geral (CARVALHO; MENDES, 2015).

No Brasil, uma vez que há uma crescente inserção das mulheres no mercado de trabalho, apesar dessa observação, a remuneração do sexo feminino apresenta uma média salarial inferior à masculina, mesmo possuindo um nível médio de instrução maior que os homens, pois estes ganham em média $60 \%$ a mais que as mulheres.

Mesmo assim, a condição de trabalhadora, permite ao Brasil abandonar o grupo de países que enfrentam deficiências gerais em educação; no entanto, segundo dados do Seminário de Oficiais e Peritos em Assuntos Populacionais do BRICS (Brasil, Rússia, Índia, China e África do Sul), ${ }^{7}$ a relação da mulher e o mercado de trabalho e a desigualdade salarial é muito latente, mesmo que em melhores condições de desenvolvimento se comparado a alguns países, como a África do Sul e a Índia, por razões de ordem cultural.

Um fator relevante, neste contexto de desvalorização do trabalho feminino é o rápido desenvolvimento da globalização hegemônica (o denominado crescimento unidimensional), vem atingindo indistintamente regiões e grupos étnicos, sendo que quem mais sofre as consequências negativas desse crescimento, são as mulheres dos países mais pobres.

E nesse sentido, como bem sustenta a tese de Isabel Turégano (2012, p. 404):

[...] la presión global em favor de ajustes estruturales, afecta especialmente a las mujeres, cuya mayor vulnerabilidade em estos Estados se agrava com problemas propios com el turismo sexual, la indústria del matrimonio y el trafico internacional de mujeres. Las mujeres de los países pobres son las que soportan la carga más flerte de la globalización coo gestoras de la pobleza, prestadoras de servicios sociales y provedoras de mano de obra barata y flexible, muchas veces parte de la economia submergida. Y las emigrantes em países desarrolhados son las que desempeñan las tareas menos valoradas y peor remuneradas, situándose muchas veces al margem de la proteción incluso formal de los Estados de origen y destino. ${ }^{8}$

7 Seminário realizado em 11 de fevereiro de 2015, segundo informações do Portal Brasil, do governo federal.

8 Tradução livre: “[...] a pressão global em favor de ajustes estruturais, afeta principalmente as mulheres cuja maior vulnerabilidade e nestes Estados se agravam com problemas próprios como o turismo sexual, a indústria do matrimônio e o sexo ou tráfico internacional de mulheres. As mulheres dos países mais pobres são as que suportam a carga mais forte da globalização como gestoras da pobreza, prestadora de serviços social e provedora de mão de obra barata e flexível muitas vezes parte de uma economia submersa. E as imigrantes em países desenvolvidos são as que desempenham as tarefas menos valoradas e pior remuneradas, situação muitas vezes a margem da proteção de inclusão formal dos Estados de origem e destino". 
Assim, em que pese terem ocorrido melhorias como as diagnosticadas pela ONU, a entrada das mulheres no mercado de trabalho, ainda assim, necessita ser revisada, com vistas ao alcance das garantias do mínimo existencial, concretizando a dignidade da pessoa humana.

Outrossim, no que se tange a maior participação das mulheres na vida política, segundo a ONU, houve um aumento da participação das mulheres nos parlamentos, sendo que em quase 90\% dos 174 países-membros signatários possuem mulheres em cargos de representação, embora, ainda, apenas uma em cada cinco membros são mulheres (ONU;PNUD, 2015).

Percebe-se, a participação das mulheres na vida pública é dificultosa, e seu engajamento somente acontece quando motivado por ideais relacionados à luta da classe por reconhecimento (HONNETH, 2004).

Há o desejo de participação feminina de construção das nações no mundo todo, mas há casos em que as mesmas são renegadas a ocupar o lugar de vítimas ou receptoras passivas das mudanças dos sistemas políticos, visto que a grande maioria dos sistemas políticos no mundo não tem complacência para com o sexo feminino (KONTULA, 2017).

As mulheres têm se identificado com projetos nacionais, cujas premissas realmente faça diferença a sua colaboração. Desse modo, na maioria das vezes as mulheres se encontram inseridas em projetos políticos ligados a sua comunidade local, o que representa uma nítida demarcação de seus limites impostos e de suas responsabilidades sociais.

Vista dessa perspectiva, as transformações sociopolíticas que passam alguns países (em atenção aos países situados na América Latina), reacende o debate acerca dos reflexos femininos na política e no desenvolvimento econômico global, a modificar a ideia de cidadania e seu papel numa agenda global (TURÉGANO, 2012).

Não obstante tenha sido o Brasil um dos primeiros países da América Latina a conceder o direito ao voto às mulheres (1934), nosso país está entre as nações que apresentam a mais baixa representação política em nosso continente. No entanto, outras nações desenvolvidas, com maior participação democrática (caso da França, por exemplo), o cenário tem sido o mesmo.

Crê-se, que sem embargos, o exercício de participação das mulheres e sua capacidade de desempenho junto à vida pública não são independentes da necessidade de formalizar suas necessidades e direitos, de modo a procurar institucionalizar as garantias que lhes são próprias. 
Ao observar o maior número de candidaturas a cargos públicos no Brasil, temos a associação direta com a emancipação feminina, mas não se pode resumir a isso.

Mesmo assim, segundo informações da Câmara dos Deputados Federais, um estudo da União Interparlamentar, ligada à Organização das Nações Unidas (ONU), colocou o Brasil em $120^{\circ}$ lugar em um ranking da proporção de mulheres nos parlamentos, o que significa estar atrás de países islâmicos como Paquistão, Sudão e Emirados Árabes Unidos (RIBEIRO, 2017).

Pois bem, apesar de todos esses avanços, existem como descrito acima, algumas lacunas a serem observadas, em especial, aos problemas relacionados às pessoas mais desprovidas de recursos, vulneráveis em razão do seu sexo, inabilidade, etnia ou localização geográfica, situações que são merecedoras de atenção e que foram elencadas como metas nos objetivos da agenda pós-2015, entre elas: a persistência da desigualdade de gênero.

Tem-se a observar, os Objetivos de Desenvolvimento do Milênio se concretiza como um grande instrumento de conscientização no cenário mundial, sendo que vários países junto a ONU, unem-se em prol do alcance de metas em comum.

O engajamento na busca da erradicação da pobreza e da desigualdade social, considerando a experiência positiva vivenciadas nos últimos quinze anos, abre espaço para uma nova agenda intitulada "Transformando Nosso Mundo a Agenda 2030 para o Desenvolvimento Sustentável", ratificada por 193 países-membros junto a ONU, numa Declaração que contempla dezessete (17) novos objetivos com 169 metas específicas, além de prever avaliações e acompanhamentos acerca do objetivo $\mathrm{n}^{0}$ 5, vale registrar: "o alcançar a igualdade de gênero e empoderar todas as mulheres e meninas" (ONU; PUND, 2015).

A nova proposta de trabalho apresenta uma visão que antevê um mundo de respeito universal aos direitos humanos e à dignidade da pessoa humana, pautado em um Estado Democrático, com parâmetros de justiça, igualdade e não discriminação (ONU; PUND, 2015).

Em suma, almeja-se reforçar a ideia de empoderamento feminino e a valorização da menina, conceitos estes que venham a desfrutar da plena igualdade sem entraves legais, econômicos e sociais, no alcance a um mundo equitativo, tolerante e aberto, razão pela qual acreditamos na firmeza de propósitos. 


\section{CONSIDERAÇÕES FINAIS}

Por todo o exposto, procurando manter a coerência entre as premissas firmadas e o objeto do presente ensaio, apresenta-se às seguintes conclusões:

1. Os Objetivos de Desenvolvimento do Milênio instituídos pela ONU compreendem o pensamento sobre os movimentos nacionais e transnacionais de proteção a igualdade entre gêneros, em especial, o ponto relacionado às demandas sociais envolvendo as mulheres e a luta por sua autonomia;

2. A meta estipulada, no que se refere às mulheres, comporta a eliminação da disparidade entre os sexos no ensino em todos os níveis de sociais, no mais tardarem até 2015, época da primeira revisão das metas propostas;

3. A questão de conscientização da importância acerca da igualdade de gênero esbarra na problemática incapacidade dos Estados em proporcionar espaços e garantias de representação das mulheres junto à sociedade civil e sua subrepresentação nas instituições políticas;

4. O Instituto de Pesquisa Econômica Aplicada - IPEA, ao mensurar a questão sobre a desigualdade de gênero e raça, desenvolveu, a pedido da ONU mulheres, dois projetos de pesquisa intitulados: "Retratos da desigualdade de Gênero e Raça" e "Sistema de Indicadores de Percepção Social: a violência contra as mulheres", os quais produziram informações significativas sobre a situação das mulheres no Brasil, destacando dados acerca da situação dos domicílios chefiados por mulheres, diferença de nível escolar, posição no mercado de trabalho, bem como a triste realidade da violência contra a mulher, no período avaliado de 1995 a 2015;

5. Segundo consta os dados de pesquisa, a ampliação do número de famílias chefiadas por mulheres parece indicar mudanças no padrão de comportamento social, ocorrendo uma mudança na auto percepção feminina em relação à sua posição dentro da família, independente do que pensam os homens na sociedade em que estão inseridas;

6. Houve aumento de acesso à educação, assim como nos últimos anos o nível de escolaridade das mulheres aumentou consideravelmente, o entanto, o diferencial de cor e de raça é onde as distâncias culturais se perpetuam, sendo que as mulheres negras ainda se encontram em desvantagem; 
7. Quanto à pesquisa "Sistema de Indicadores de Percepção Social: a violência contra as mulheres", segundo a pesquisa encomendada pela ONU mulheres junto ao IPEA, os dados são alarmantes e contraditórios. O modelo patriarcal e heteronormativo de sociedade ainda predominam, apesar das mudanças sociais e inclusão da mulher como chefe de família. Persiste, embora silenciosa em todas as classes sociais, a aceitação da violência doméstica (psicológica), de maneira subliminar;

8. As informações do último relatório (2015) divulgado pela ONU sobre os Objetivos de Desenvolvimento do Milênio apontam, no que se refere à promoção de igualdade de gênero e autonomia das mulheres, tal meta não foi totalmente satisfatória; contudo apresentou alguns avanços, principalmente na área de educação. A diferença de gênero está muito presente nas carreiras seguidas pelas mulheres e homens, um aspecto que evidencia o desempenho do meio escolar na formação de valores à formação das identidades de gênero;

9. A participação das mulheres no mercado de trabalho cresceu consideravelmente conforme as avalições da ONU, todavia no Brasil lideramos o ranking dos países com maior disparidade salarial, se comparados com outros países menos desenvolvidos;

10. O processo de globalização influência negativamente processo de busca pela igualdade de gênero. As mulheres oriundas dos países menos desenvolvidos são as que mais sofrem com o aumento da prostituição, exploração sexual, tráfico internacional de mulheres, assim como com o exercício de atividades pouco valorizadas e de baixa remuneração quando emigrantes em países desenvolvidos.

11. Na vida política, segundo a ONU, houve um aumento da participação das mulheres nos parlamentos, todavia o Brasil se encontra em $120^{\circ}$ lugar em um ranking da proporção de mulheres nos parlamentos índice baixo se comparado a outros países;

12. Por derradeiro, a nova agenda intitulada "Transformando Nosso Mundo a Agenda 2030 para o Desenvolvimento Sustentável", contempla dezessete (17) novos objetivos com 169 metas específicas, prevendo como complementar ao objetivo outrora radicado, a mantença em promover à igualdade de gênero e empoderar todas as mulheres e meninas ao livre exercício de sua autonomia. 


\section{REFERÊNCIAS}

BARBOSA, Heloisa Helena Gomes; ALMEIDA JÚNIOR, Vitor de Azevedo de. (Des)igualdade de gênero: restrições à autonomia da mulher. Pensar-Revista de Ciências Jurídicas. Fortaleza, v. 22, n.1, p. 240-271, jan./abr. 2017.

CARVALHO, Guilherme Paiva de; MENDES, Marcília Gomes. Gênero e políticas educacionais no Brasil. Caderno Espaço Feminino. Uberlândia/MG, v. 28, n.1, p. 7-23, jan./jun. 2015.

CENTRO DE VOLUNTARIADO DE SÃO PAULO. Breve avaliação dos Objetivos de Desenvolvimento do Milênio (ODM). Disponível em:

<http://www.objetivosdomilenio.org.br/escolas/>. Acesso em: 10 de jun. 2017.

Oito jeitos de mudar o mundo. Disponível em:

<http://www.objetivosdomilenio.org.br/>. Acesso em: 08 de jun. 2017.

CORRALO, Giovani da Silva; GIRELLI, Camile Serraglio. A hermenêutica diatópica como forma de diálogo entre nações multiculturais na aplicação dos direitos femininos na pósmodernidade. Revista Justiça do Direito. Passo Fundo, v. 29, n.3, p. 372-388, set./dez. 2015.

INSTITUTO DE PESQUISA ECONÔMICA APLICADA (IPEA). Retrato da desigualdade de gênero e raça. Disponível em:

<http://www.ipea.gov.br/portal/index.php?opition=com_content\&view=article\&id=170306>. Acesso em: 29 de maio 2017.

. Sistema de Indicadores de Percepção Social (SIPS). Disponível em:

$<$ http://www.ipea.gov.br/portal/index.php?opition=com_content\&view=article\&id=140327_s ips_violencia_contra_mulheres>. Acesso em: 06 de jun. 2017.

GARCIA, Denise Schimitt Siqueira; GARCIA, Heloise Siqueira. Objetivos de Desenvolvimento do Milênio e as novas perspectivas do desenvolvimento sustentável pela Organização das Nações Unidas. Revista da Faculdade de Direito da UFRGS. Porto Alegre, v. especial, n.35, p. 192-206, dez./2016.

GIDDENS, Anthony. Sociologia. Lisboa: Fundação Calouste Gulbenkian, 2007.

HONNETH, Axel. Luta por reconhecimento: a gramática moral dos conflitos sociais. São Paulo: Editora34, 2003.

KONTULA, Anna. As mulheres têm que ser perfeitas se querem ter sucesso. Disponível em: <http://www.dn.pt/mundo/interior/as-mulheres-tem-de-ser-perfeitas-se-querem-tersucesso-8489446.html>. Acesso em: 18 de jun. 2017.

LANGE, Jadel Queralt. El igualitarismo de la suerte. DOXA, Cuadernos del Filosofia Del Derecho. Alicante (Espanha): n. 38, p. 189-213, 2015.

ORGANIZAÇÃO DAS NAÇÕES UNIDAS (ONU). Declaração do Milênio. Disponível em:<http://www.pnud.org.br/docs/declaracao_do_milenio.pdf> Acesso em: 15 de jun. 2017. 
Cúpula das Nações Unidas sobre o Desenvolvimento Sustentável, nova agenda de desenvolvimento sustentável: não deixando ninguém para trás. Disponível em: <http://www.nacoesunidas.org/pos2015/cupula/> Acesso em: 11 de jun. 2017.

PORTAL BRASIL. Participação feminina no mercado de trabalho. Disponível em: < http://www.brasil.gov.br/governo/2015/02/participacao-feminina-no-mercado-de-trabalhoesta-aumentando>. Acesso em: 19 de jun. 2017.

RAMOS, Edith Maria Barbosa. A universalização da saúde. Manaus: UFMA, 2014.

RIBEIRO, Paulo Silvino. Participação da Mulher na vida política. Brasil Escola.

Disponível em <http://brasilescola.uol.com.br/sociologia/participacao-mulher-na-vidapolitica.htm>. Acesso em: 19 de jun. 2017.

TURÉGANO, Isabel. Mujeres, ciudadanía y globalización. DOXA, Cuadernos del Filosofia Del Derecho. Alicante (Espanha): n. 35, p. 393-412, 2012. 